\title{
INFECÇÃO EM CIRURGIA DE EMERGÊNCIAS E TRAUMA: PREVENÇÃO, DIAGNÓSTICO E TRATAMENTO
}

\author{
INFECTION IN EMERGENCY AND TRAUMA SURGERY: PREVENTION, DIAGNOSIS AND TREATMENT
}

Antonio Ziliotto Júnior

Médico. Unidade de Emergência do Hospital das Clínicas da Faculdade de Medicina de Ribeirão Preto - USP. Docente de Cirurgia e Coordenador do Internato de Cirurgia Geral. Universidade de Ribeirão Preto.

CorRespondência: Rua João Nogueira de Carvalho, 250. Ribeirânia. 14096-150 Ribeirão Preto - SP. e-mail: aziliotto@uol.com.br

Ziliotto Júnior A. Infecção em cirurgia de emergências e trauma: prevenção, diagnóstico e tratamento. Medicina (Ribeirão Preto) 2007; 40 (3): 329-34, jul./set.

RESUMO: A infecção continua sendo a maior causa de morbidade e de mortalidade em pacientes traumatizados ou submetidos a cirurgia de emergência, apesar dos esforços na prevenção e nos avanços na terapia antimicrobiana. A infecção pode surgir no local do trauma ou na via de acesso para o tratamento cirúrgico, mas a mais importante é a infecção hospitalar, que ocorre em geral fora do sítio cirúrgico ou do local de trauma, como as pneumonias, infecções do trato urinário e relacionadas às punções vasculares. São determinantes da infecção o número e a virulência da bactéria e por outro lado a resistência do hospedeiro. Também são fatores predisponentes o choque, a hipoxemia, as transfusões sanguíneas, a hipotermia, a má nutrição, o alcoolismo crônico e o diabete, dentre outras. Para evitar a infecção devem ser adotadas práticas adequadas de controle da infecção tanto local quanto sistêmico.

Descritores: Infecção da Ferida Operatória. Abdome Agudo. Infecção Hospitalar. Cateterismo Venoso. Trauma.

\section{1- INTRODUÇÃO}

Quando se analisam as causas de morbidade e de mortalidade relacionadas às cirurgias de modo geral, e ao trauma, em especial, observa-se que a infecção tem papel importante, tanto na primeira fase de atendimento, mas principalmente no segundo pico de mortalidade, que ocorre passados os primeiros dias do tratamento. Apesar de o paciente já poder apresentar infecção ao ser atendido é mais comum que ela venha a ter origem hospitalar, e com mais freqüência nos doentes graves que demandam, durante sua evolução, permanência em unidades de terapia intensiva.

Com os avanços dos conhecimentos e a incorporação de tecnologia no tratamento dos pacientes, a perspectiva de sobrevivência tem aumentado significativamente. Entretanto essa maior sobrevida está li- gada a um maior tempo de internação hospitalar, muitas vezes em centros de tratamento avançado, o que aumenta a probabilidade de instalação das infecções.

Ao lado de um conjunto cada vez mais sofisticado de meios de diagnóstico, tem havido também um acréscimo importante nas opções terapêuticas. A exemplo, pode-se contar hoje com uma ampla variedade de antimicrobianos para o tratamento das mais variadas situações infecciosas. Entretanto, lamentavelmente a resistência dos microrganismos a essas drogas caminha par e passo com esses avanços.

\section{2- ABORDAGEM GERAL}

As alterações infecciosas podem aparecer no sítio do trauma, nas áreas ligadas ao tratamento cirúrgico ou relacionadas às manobras executadas durante 
o tratamento do paciente. Desde que haja quebra da barreira natural, pelas incisões cirúrgicas ou pelos mecanismos de trauma, há abertura de porta para que os microrganismos adentrem o organismo. O próprio grau de gravidade do trauma, medido por sistemas padronizados ("TRISS, ISS, RTS, NISS"), parece ser fator preditivo para o surgimento de infecção. ${ }^{1}$

A simples presença de bactérias nos sítios lesados não significa necessariamente que seja instalada uma infecção. Para que ela se estabeleça é necessário que haja quebra do equilíbrio entre defesa do organismo, a virulência da bactéria e o número de microrganismos presentes. Também vários fatores ligados ao sítio comprometido são importantes para que a infecção se instale principalmente a isquemia local, extensão do tecido necrótico e presença de corpos estranhos no local. Ainda são fatores predisponentes, a manutenção de espaço morto na área lesada, a formação de hematomas e a presença de coleções serosas resultantes de necrose tecidual, que constituem verdadeiros meios de cultura para as bactérias.

A primeira linha de defesa do organismo é a barreira mecânica representada pela pele e mucosas. Uma vez ultrapassada esta barreira, a presença de fatores desencadeantes dá início a uma complexa série de reações orgânicas que constituem a resposta inflamatória. ${ }^{2}$ Essas defesas ficam prejudicadas na presença de choque e, por conseqüência, má perfusão e oxigenação teciduais, na hipotermia, em doentes politransfundidos, imunodeprimidos, diabéticos, desnutridos e no alcoolismo. ${ }^{3}$ A avaliação adequada desses fatores é crucial para a consideração do tratamento e da prevenção das infecções de modo geral.

Alguns fatores ligados ao trauma podem ser, por si, responsáveis por infecção. Um ferimento perfurante da pele e tecido celular subcutâneo por uma faca limpa é muito menos propício ao desenvolvimento de infecção do que, por exemplo, uma lesão com laceração e descolamento de tecidos, perda de substância e com presença de corpos estranhos. No atendimento de pacientes com feridas deste último tipo são fundamentais a limpeza e o desbridamento, com remoção de todo tecido desvitalizado, de toda sujeira e corpos estranhos, além da evacuação de eventuais hematomas. Tal lavagem pode ser feita simplesmente com água corrente sem necessidade de soluções estéreis. ${ }^{4} \mathrm{O}$ emprego de soluções anti-sépticas para a limpeza como, por exemplo, os derivados de iodo é discutível e parece causar mais lesão do que benefício. ${ }^{5}$

O fechamento primário dessas feridas somente deve ser considerado se elas estiverem seguramente limpas. Caso contrário é preferível mantê-las abertas para cicatrização por segunda intenção, ou então indicar fechamento terciário. Quando permanecer sangramento difuso na incisão cirúrgica, ou se existir edema ou qualquer outro fator que vá promover exsudação, situações essas que podem levar ao aparecimento de hematoma ou de outra coleção na parede, devem-se empregar táticas que promovam pressão negativa e aspiração contínua por meio de suctores. ${ }^{6} \mathrm{O}$ uso de antibióticos habitualmente é restrito à profilaxia. A terapia sistêmica subseqüente parece não reduzir as taxas de infecção de parede, mas muda a característica da flora infectante ${ }^{7}$. Entretanto, ela é recomendada nas feridas já contaminadas quando do atendimento e quando houver evidências de propagação da infecção pelos tecidos moles adjacentes, celulite ou em certas condições ligadas ao hospedeiro que apresente algum grau de baixa resistência. Quadros muito graves de infecção acontecem quando há descolamentos importantes, com surgimento de fasciite necrotizante e de gangrena gasosa.

Deve-se salientar que os tratamentos adjuvantes empregados no manuseio das feridas infectadas, nos quais se enquadra até a oxigenioterapia hiperbárica, não devem substituir os cuidados adequados com as feridas, com limpeza rigorosa e desbridamentos ${ }^{3}$.

\section{3- ABORDAGEM ESPECÍFICA}

\section{1- Incisões cirúrgicas}

A prevenção da infecção deve ser destacada para intervenções cirúrgicas de urgência e eletivas. Os cuidados habituais de lavagem com água e sabão da área a ser abordada, anti-sepsia com produtos de confirmada eficácia, como os derivados de iodo e a clorexidina $^{8}$, proteção da parede após a abertura, cuidados com a parede para evitar lesões isquêmicas causadas pelos retratores são comuns a ambas situações. No entanto, na urgência podem-se deparar com situações que interferem na decisão do cirurgião. A presença de contaminação importante pode levar à opção de um fechamento secundário da parede. Devese considerar ainda fechamento retardado na vigência de choque, transfusões múltiplas, lesões extensas em cólon, ou mesmo do delgado quando abordada com mais de duas horas de evolução. Outros aspectos que têm sido muito valorizados na prevenção da infecção são a manutenção da temperatura corporal, evitando a hipotermia, o controle da glicemia e oxigenioterapia adequada. A preocupação com a temperatura corpo- 
ral é particularmente importante na criança e apenas o controle do ambiente cirúrgico não é suficiente, devendo-se usar colchões térmicos apropriados ${ }^{3}$.

\section{2- Cavidade abdominal}

A conduta adotada quando houver lesão intestinal é norteada pelo local onde a lesão ocorreu. Sabese que a população bacteriana, praticamente insignificante no estômago, aumenta a partir do jejuno até o reto. No ceco encontram-se $10^{6}$ a $10^{7}$ bactérias por grama de fezes e no sigmóide, cerca de $10^{10} \mathrm{bact} / \mathrm{g}{ }^{7}$. Essas bactérias, uma vez caindo na cavidade peritoneal, distribuem-se pelo líquido peritoneal, o qual se movimenta com a dinâmica respiratória, acumulando-se nos espaços sub-frênicos, sub-hepático, no fundo de saco e nas goteiras parietocólicas. Além da população bacteriana presente, o material fecal extravasado é constituído por corpos estranhos que vão agravar a infecção. Como parte do tratamento, a lavagem sistemática da cavidade com soro morno visa, além de diminuir ao máximo a população bacteriana presente, remover todos esses corpos estranhos, e também os debris e a fibrina eventualmente presentes. Por outro lado, a antibioticoterapia sistêmica é indicada, baseada inicialmente na flora Gram negativa e anaeróbica predominante.

Essa preocupação com a limpeza tem por principais finalidades a redução do risco de sepse causada pelas toxinas bacterianas e prevenção dos abscessos abdominais. Os drenos, tubulares ou laminares, colocados na cavidade com essa pretensão, não cumprem na verdade a finalidade proposta. Eles são muito cedo bloqueados pelas alças intestinais, vísceras e pelo omento e, quando o abscesso se formar, não conseguem drenar o conteúdo das lojas formadas.

O diagnóstico presuntivo dessa complicação é clinico, baseado em sinais e sintomas como dor, febre, íleo prolongado, retenção hídrica, intolerância à alimentação enteral, e o leucograma mostrará leucocitose em graus variados, com desvio à esquerda. Dentre os métodos de imagem usados para confirmação, a ultrasonografia é o mais freqüentemente indicado, pelas informações relativamente seguras que fornece, pela praticidade e pelo baixo custo. Entretanto, as modernas tomografias fornecem dados muito mais seguros, tendo maior sensibilidade e especificidade. ${ }^{9}$ Existem outros métodos muito interessantes como a cintilografia com leucócitos marcados, com elevada especificidade, mas que não encontra aplicação na prática clínica diária, assim como a ressonância magnética. ${ }^{10}$ Esses exames são usados para casos muito especiais, quando existe dificuldade diagnóstica pela tomografia, em razão de distorções anatômicas decorrentes do processo inflamatório. Tanto a tomografia como a ultra-sonografia se prestam também como auxiliares para a terapêutica cirúrgica, possibilitando a intervenção por meio de punções guiadas para evacuação e drenagem dos abscessos.

\section{3- Cavidade torácica}

O tórax é freqüentemente afetado por lesões traumáticas, e a cavidade torácica pode ser sede de processos infecciosos. A contaminação pode vir de objetos penetrantes contaminados, mas é mais comumente associada ao uso de drenos usados no tratamento de hemo ou pneumotórax. Por isso, devem ser tomados cuidados rigorosos de anti-sepsia quando da drenagem pleural, além de assegurar o esvaziamento completo do sangue e coágulos coletados no espaço pleural. Como ja foi salientado, coleções de sangue e tecido necrótico levam ao crescimento de bactérias e desenvolvimento de empiema. Conquanto seja assunto controvertido, a antibioticoterapia empregada durante todo o tempo de drenagem torácica não se tem mostrado necessária. ${ }^{7}$

Quando há evolução para empiema, e o microrganismo encontrado nas culturas for um germe Gram negativo, deve-se considerar a possibilidade de processo infecciosos sub-diafragmático.

\section{4- INFECÇÕES SISTÊMICAS}

Após o atendimento inicial ao paciente, e adotadas as medidas cabíveis em cada caso, se inicia a segunda fase de problemas ligados às infecções. Agora com novas características, passam a ter conotações diferentes, relacionadas com os diferentes microrganismos envolvidos. São as infecções designadas como hospitalares. Não é improvável que uma infecção presente na fase inicial do atendimento possa mudar de característica e ser colonizada por bactérias mais agressivas e multi-resistentes, provenientes na flora bacteriana hospitalar. Entretanto, frequentemente essas infecções se caracterizam por ocorrerem à distância do local de trauma ou da cirurgia. Aparecem sob forma de pneumonias, infecções do trato urinário e ligadas aos cateterismos vasculares.

Os pacientes hospitalizados por tempo maior que uma semana já podem ter suas vias aéreas colonizadas por um conjunto de microrganismos presentes na flora hospitalar, com graus variáveis de resistência antibiótica ${ }^{7}$. Quaisquer mecanismos que venham 
quebrar a resistência orgânica, local ou geral, propiciam o surgimento da infecção. A pneumonia é a principal causa de morte dentre as infecções hospitalares. Sua prevalência em unidades de terapia intensiva chega a $65 \%$ e a letalidade até $55 \%{ }^{7}$ Nos pacientes com ventilação mecânica, essa possibilidade é significativamente maior, não apenas pelas mudanças na dinâmica respiratória, mas também pelos traumatismos causados pelas cânulas, que podem lesar o trato respiratório e abrir portas de entrada aos microrganismos. Além disso, são doentes em geral mais graves, com alterações da resistência orgânica e, portanto mais susceptíveis às infecções. ${ }^{11}$

A infecção do trato urinário é outra condição muito freqüentemente ligada à cirurgia ou trauma e é responsável por cerca de $40 \%$ das infecções hospitalares. ${ }^{12}$ Essas situações, diferentemente do que acontece nas infecções comunitárias ${ }^{13}$, são comumente associadas ao cateterismo vesical realizado com prática inadequada. Pode também ser causada por traumatismos uretrais ou no trígono vesical durante a passagem da sonda, propiciando meio para a invasão bacteriana, ou então pelo manuseio inadequado da sonda e do conjunto coletor, levando à progressão retrógrada de bactérias nos pacientes com oligúria. A profilaxia desta infecção se fundamenta no emprego de técnicas corretas de cateterismo, executado com todo rigor de anti-sepsia. A sonda deve ser removida tão logo cesse sua absoluta necessidade. Não é incomum se observar pacientes em enfermaria ou mesmo em unidades de terapia intensiva sondados desnecessariamente.

O cateterismo intravascular, venoso em sua maioria, periférico ou central, é parte integrante e comum no tratamento de pacientes traumatizados ou cirúrgicos. Essas punções funcionam como portas de entrada de microrganismos que vão ser responsáveis pela infecção tanto no local da punção quanto sistêmica, por êmbolos sépticos liberados a partir do cateter. ${ }^{14}$ Como fazem parte indispensável do tratamento devem, pelo menos, ser realizadas com todo o rigor técnico. Por exemplo, múltiplas perfurações da pele na tentativa de cateterismo, resultam em múltiplos pontos de entrada de bactérias. O local a ser puncionado deve ser tratado como fosse um campo a ser operado, com limpeza prévia e anti-sepsia. ${ }^{8}$ Após o procedimento, os cuidados devem ser tomados não só com o cateter mas com o manuseio de todo o conjunto usado para as infusões de soluções. Não existe consenso sobre o tempo de permanência dos cateteres. Os periféricos são associados a uma maior inci- dência de flebite comparativamente aos centrais. ${ }^{14}$ Apesar dessa discussão é aconselhável substituir as punções periféricas a cada três a quatro dias e as centrais a cada dez a quinze dias, na dependência da observação rigorosa das condições inflamatórias ou infecciosas no local da punção. Sempre após sua retira$\mathrm{da}$, o cateter deve ser enviado para cultura, pois esta informação será de grande utilidade caso venham a surgir ulteriormente sinais de infecção.

\section{5- PROFILAXIA DO TÉTANO}

O tétano decorrente de acidentes é adquirido através da contaminação dos ferimentos, independentemente de seu tamanho, inclusive de ferimentos superficiais extensos e queimaduras extensas, com esporos do Clostridium tetani, que são encontrados no ambiente. Sob condições favoráveis de anaerobiose, como em feridas com tecido necrótico, corpos estranhos ou mesmo sujeira, os esporos germinam para a forma vegetativa do Clostridium tetani, multiplicam-se e passam a produzir a tetanospasmina. Essa neurotoxina atua nas terminações nervosas induzindo contraturas musculares intensas, podendo ser letal em humanos em concentrações tão baixas quanto 2,5 nanogramas/quilograma de peso ${ }^{7}$. É parte integrante dos cuidados no atendimento dos pacientes traumatizados a observância dos cuidados profiláticos desta grave afecção. No quadro abaixo apresentamos as orientações preconizadas pelo Centro de Vigilância Epidemiológica para essa profilaxia (Tabela I). ${ }^{15}$

A vacina contra o tétano e o soro antitetânico não devem ser administrados no mesmo local anatômico. Não há indicação para o emprego da penicilina benzatina ou outros antimicrobianos voltados para o tratamento específico do Clostridium tetani.

\section{6- CONCLUSÃO}

$\mathrm{Na}$ abordagem dos pacientes traumatizados ou submetidos a operações e procedimentos de emergência, é de fundamental importância que se tomem todos os cuidados para evitar as infecções. A atenção deve estar voltada para suas condições gerais do paciente como choque, hipoxemia, hipotermia, estado nutricional, dentre outros, bem como para as afecções locais. As feridas devem ser tratadas com limpeza e desbridamentos, mas principalmente atuando no sentido profilático, empregando técnicas corretas de antisepsia nos procedimentos cirúrgicos e punções. 
Tabela I: Profilaxia do tétano em casos de ferimentos ${ }^{13}$

\section{História de imunização contra o tétano (DTP, DT, dT ou TT)}

Tipo de ferimento

Ferimento leve não contaminado
Incerta ou menos de 3 doses

Esquema

Se menor de 7 anos, aplicar DTP completando 3 doses, com intervalos de 2 meses (mínimo 30 dias).

\section{3 ou mais doses}

Esquema

Só aplicar a vacina (dT) se tiverem decorridos mais de 10 anos da última dose.

Se 7 anos ou mais, aplicar dupla (dT), completando 3 doses, com intervalo de 2 meses (mínimo 30 dias).

Não aplicar o soro antitetânico

Não aplicar o soro antitetânico (homólogo ou heterólogo).

Todos os outros ferimentos inclusive punctóricos
Se menor de 7 anos, aplicar DTP completando 3 doses, com intervalos de 2 meses (mínimo 30 dias).

Se 7 anos ou mais, aplicar dupla (dT), completando 3 doses, com intervalo de 2 meses (mínimo 30 dias).

Aplicar o soro antitetâncio.

Soro heterólogo - administrar 5.000 unidades, por via intramuscular, após tratamento preventivo de anafilaxia.

Soro homólogo - administrar via intramuscular, 250 unidades com título de 1:400, ou dosagem equivalente com outro título.
Só aplicar a vacina (dT) se tiverem decorridos mais de 10 anos da última dose.

Não aplicar o soro antitetânico (homólogo ou heterólogo).

Ziliotto Júnior A. Infection in emergency and trauma surgery: prevention, diagnosis and treatment. Medicina (Ribeirão Preto) 2007; 40 (3): 329-34, july/sept.

ABSTRACT: Infection remains the major cause of morbidity and mortality in trauma patients and in patients submitted to emergency operations, despite preventive strategies and potent antibiotics. The infection can appear as wound infection at the site of injury or at the route employed for its repair. The most important kind of infection is the nosocomial one, referring to those that occur remote from the site of injury or operation as pneumonia, urinary tract infection, and related to the intravascular catheter. The number of bacteria, its virulence and poor host defense are determinants of infection. Shock, hypoxemia, blood transfusion, systemic hypothermia, malnutrition, chronic alcoholism, diabetes are factors that predispose to infection. To avoid this condition, prevention begins with appropriate local and systemic practices of infection control.

Keywords: Surgical Wound Infection. Abdomen, Acute. Cross Infection. Catheterization, Venous. Trauma. 


\section{REFERÊNCIAS}

1 - Jamulitrat S, Narong MN, Thongpiyapoom S. Trauma severity score system as predictors of nosocomial infection. Infect Control Hosp Epidemiol 2002; 23: 268-73.

2 - Rocha e Silva R, Birolini D. Infecção e imunologia no trauma. In: Birolini D, Utiyama E, Steinman E, editores. Cirurgia de emergência.1a ed. São Paulo: Atheneu; 1996. p32-46.

3 - Ueno C, Hunt TK, Hopf HW. Using physiology to improve surgical wound outcomes. Plast Reconstr Surg 2006; 117: 59S$71 \mathrm{~S}$

4 - Hall S. A review of the effect of tap water versus normal saline on infection rates in acute traumatic wounds. J Wound Care 2007; 16: 38-41.

5 - Khan MN, Naqvi AH. Antiseptics, iodine, povidone iodine and traumatic wound cleansing. J Tissue Viability 2006; 16: 6-10.

6 - Stannard JP, Robinson JT, Anderson ER, McGwin G, Volgas DA, Alonso JE. Negative pressure wound therapy to treat hematomas and surgical incisions following high-energy trauma. J Trauma 2006; 60: 1301-6.

7 - Fry DE. Prevention, diagnosis, and management of infection. In: Moore EE, Feliciano DV, Mattox KL, editors. Trauma. 5th ed. New York:McGraw-Hill:2004. p. 355-81.

8 - Adams D, Elliot TS. Skin antiseptics used prior to intravascular catheter insertion. Br J Nurs 2007; 16: 278-80.
9 - Marco GG, Diego S, Giulio A, Luca S. Screening US and CT for blunt abdominal trauma: a retrospective study. Eur $\mathrm{J}$ Radiol 2005;56:97-101.

10 - Gupta H, Dupuy DE. Advances in imaging of the acute abdomen. Surg Clin North Am 1997;77:1245-63.

11 - Andermahr J, Greb A, Henler T, Helling HJ, Bouillon B, Sauerland S, Rehm KE, Neugebauer E. Pneumonia in multiple injured patients: a prospective controlled trial on early prediction using clinical and immunological parameters. Inflamm Res 2002; 51: 265-72.

12 - Kalsi J, Arya M, Wilson P, Mundy A. Hospital-acquired urinary tract infection. Int J Clin Prat 2003; 57: 388-91.

13 - Vieira Neto OM. Infecção do trato urinário. Medicina ( Ribeirão Preto) 2003; 36: 365-9.

14 - Kovacevich DS, Papke LF. Guidelines for the prevention of intravascular catheter-related infections: Center for disease control and prevention. Nutr Clin Pract 2003: 18:95-6.

15 - Centro de Vigilância Epidemiológica - Programa Estadual de Imunização. Disponível em http://www.cve.saude.sp.gov.br/ htm/imuni/Cve_pni.htm, acessado em agosto de 2007.

Recebido em: 26/06/2007

Aprovado em: 05/09/2007 